\title{
Proinflammatory and cytotoxic response to nanoparticles in precision-cut lung slices
}

\author{
Stephanie Hirn ${ }^{* 1}$, Nadine Haberl ${ }^{1}$, Kateryna Loza ${ }^{2}$, Matthias Epple ${ }^{2}$, \\ Wolfgang G. Kreyling ${ }^{3}$, Barbara Rothen-Rutishauser ${ }^{4}$, Markus Rehberg ${ }^{1}$ \\ and Fritz Krombach ${ }^{1}$
}

\section{Full Research Paper}

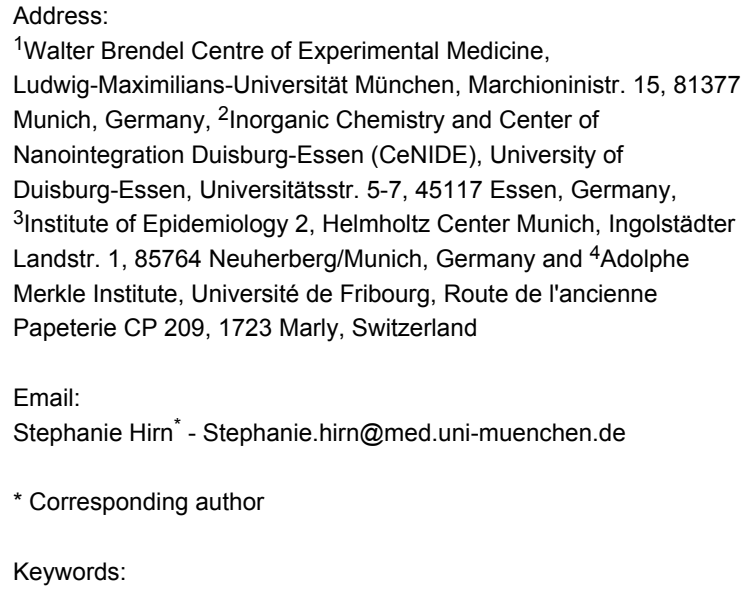

${ }^{1}$ Walter Brendel Centre of Experimental Medicine, Ludwig-Maximilians-Universität München, Marchioninistr. 15, 81377 Munich, Germany, ${ }^{2}$ Inorganic Chemistry and Center of Nanointegration Duisburg-Essen (CeNIDE), University of Duisburg-Essen, Universitätsstr. 5-7, 45117 Essen, Germany, ${ }^{3}$ Institute of Epidemiology 2, Helmholtz Center Munich, Ingolstädter Landstr. 1, 85764 Neuherberg/Munich, Germany and ${ }^{4}$ Adolphe Merkle Institute, Université de Fribourg, Route de l'ancienne Papeterie CP 209, 1723 Marly, Switzerland

Email:

Stephanie Hirn ${ }^{*}$ - Stephanie.hirn@med.uni-muenchen.de

* Corresponding author

Keywords:

cytokines; cytotoxicity; ex vivo; lung slices; nanoparticles
Beilstein J. Nanotechnol. 2014, 5, 2440-2449. doi:10.3762/bjnano.5.253

Received: 19 March 2014

Accepted: 25 November 2014

Published: 18 December 2014

This article is part of the Thematic Series "Biological responses to NPs". Guest Editor: R. Zellner

(c) 2014 Hirn et al; licensee Beilstein-Institut. License and terms: see end of document.

\begin{abstract}
Precision-cut lung slices (PCLS) are an established ex vivo alternative to in vivo experiments in pharmacotoxicology. The aim of this study was to evaluate the potential of PCLS as a tool in nanotoxicology studies. Silver (Ag-NPs) and zinc oxide (ZnO-NPs) nanoparticles as well as quartz particles were used because these materials have been previously shown in several in vitro and in vivo studies to induce a dose-dependent cytotoxic and inflammatory response. PCLS were exposed to three concentrations of $70 \mathrm{~nm}$ monodisperse polyvinylpyrrolidone (PVP)-coated Ag-NPs under submerged culture conditions in vitro. ZnO-NPs (NM110) served as 'soluble' and quartz particles (Min-U-Sil) as 'non-soluble' control particles. After 4 and $24 \mathrm{~h}$, the cell viability and the release of proinflammatory cytokines was measured. In addition, multiphoton microscopy was employed to assess the localization of Ag-NPs in PCLS after $24 \mathrm{~h}$ of incubation. Exposure of PCLS to ZnO-NPs for 4 and $24 \mathrm{~h}$ resulted in a strong decrease in cell viability, while quartz particles had no cytotoxic effect. Moreover, only a slight cytotoxic response was detected by LDH release after incubation of PCLS with 20 or $30 \mu \mathrm{g} / \mathrm{mL}$ of Ag-NPs. Interestingly, none of the particles tested induced a proinflammatory response in PCLS. Finally, multiphoton microscopy revealed that the Ag-NP were predominantly localized at the cut surface and only to a much lower extent in the deeper layers of the PCLS. In summary, only 'soluble' ZnO-NPs elicited a strong cytotoxic response. Therefore, we suggest that the cytotoxic response in PCLS was caused by released $\mathrm{Zn}^{2+}$ ions rather than by the $\mathrm{ZnO}-\mathrm{NPs}$ themselves. Moreover, Ag-NPs were predominantly localized at the cut surface of PCLS but not in deeper regions, indicating that the majority of the particles did not have the chance to interact with all cells present in the tissue slice. In conclusion, our findings suggest that PCLS may
\end{abstract}


have some limitations when used for nanotoxicology studies. To strengthen this conclusion, however, other NP types and concentrations need to be tested in further studies.

\section{Introduction}

Nanoparticles (NPs) are defined as materials with one dimension between 1-100 $\mathrm{nm}$ that occur naturally or anthropogenically. The class of synthetic NPs can be subdivided in incidental NPs that are generated as byproducts of combustion processes (e.g., in diesel exhaust) and engineered NPs (ENPs) that are specifically manufactured. The synthesis of ENPs allows one to control the properties of NPs such as size, shape, or chemical composition. As nanotechnology is a tremendously growing field with high commercial interest, ENPs are already used in several areas such as car industry, power engineering, optics, cosmetics, medicine, and pharmaceutics. This wide application range also raises questions about the safety of ENPs. Toxicological testing for most commercial ENPs is missing so far as there is no regulation for the fabrication and declaration of ENPs in consumer products. Assigned with the task to determine potential health risk effects of ENPs, nanotoxicology is a rapidly emerging research area [1]. There are several in vitro and in vivo models for testing the toxicity of nanoparticles. In vitro test systems, offering the advantages of easy handling and high-trough-put screening, can provide a first estimation of possible toxic effects. However, cell culture systems do not adequately reflect the real in vivo situation, whereas animal experiments are elaborative, cost-intensive, and the transferability from animal to human is often difficult. Furthermore, the aspect of the three "R's" (replacement, refinement, and reduction of animal experiments) makes the development of in vitro or ex vivo alternatives a worthwhile objective [2,3]. Therefore, tissue slices can be an alternative to in vitro and in vivo studies [4]. Precision-cut lung slices (PCLS) are already used as an alternative ex vivo model in lung pharmacotoxicology [5]. As the lungs are also an important primary target organ for aerosolized ENPs, PCLS could have the potential to serve as an efficient tool in nanotoxicology. PCLS can be prepared from several species such as mouse or rat, but also from human lung tissue [6]. A major advantage of this tissue model is the retention of the lung architecture. The conservation of intact cells, including alveolar epithelial cells, alveolar macrophages, and dendritic cells, in their natural context has been shown in several studies by immunohistochemical staining [7-9]. Nevertheless, this in vitro system has also its limitations. There are obvious disadvantages in comparison to the in vivo situation such as no ventilation, no stretching, and no perfusion of the tissue. Moreover, dead cells are present at the slice surface due to the cutting process [10]. However, airway dynamics are preserved in PCLS which allows the monitoring of bronchoconstriction triggered by chemical stimuli [11-13].
So far, PCLS are already used in pharmacotoxicology studies to determine the response to allergens, chemicals, tobacco smoke, engine emissions, or oxidant air pollutions [5]. These studies mostly focused on the evaluation of airway constriction in PCLS caused by the tested substances $[11,13,14]$. Despite their established usage in pharmacotoxicology, there are only a few studies using PCLS in the field of nanotoxicology, yet. It was demonstrated that solid lipid NPs induced a cytotoxic response in PCLS, but only at very high concentrations $(1 \mathrm{mg} / \mathrm{mL}$ and higher) [15-18]. Wohlleben et al. reported that a cobalt ferrite nanomaterial elicited a dose-dependent cytotoxicity as determined by the water-soluble tetrazolium salt (WST-1) assay and that incubation of PCLS with carbon nanotubes did not induce a cytotoxic response, whereas exposure to $\mathrm{ZnO}-\mathrm{NPs}$ induced a strong cytotoxic response in PCLS [19,20].

The aim of the present study was to investigate whether PCLS have the potential to serve as a generally applicable effective tool in nanotoxicology. First, we determined the viability of PCLS up to $72 \mathrm{~h}$ by carrying out live/dead staining, lactate dehydrogenase (LDH) assay, and WST-1 assay. Second, we assessed the cytotoxic and proinflammatory response of PCLS to Ag-NPs through LDH assay, WST-1 assay, and ELISA assay for CXCL-1 and tumour necrosis factor- $\alpha$ (TNF- $\alpha$ ) release. $\mathrm{ZnO}-\mathrm{NPs}$ served as a soluble control and quartz particles as a non-soluble control, since both particle types have induced cytotoxic as well as inflammatory responses in in vitro as well as in vivo assays.

\section{Results}

\section{Particle characterization}

The mean hydrodynamic diameter of the Ag-NPs as determined by dynamic light scattering (DLS) was $116 \mathrm{~nm}$ and the polydispersity index (PDI) was below 0.3 for all measurements. The mean diameter of the metallic core as determined by scanning electron microscopy (SEM) was $65 \mathrm{~nm}$. Furthermore, the mean hydrodynamic diameter of the Ag-NPs in culture medium (DMEM/F-12 Ham) as measured by DLS was $120 \mathrm{~nm}$. The mean hydrodynamic diameter of the uncoated $\mathrm{ZnO}-\mathrm{NP}$ (NM-110) in distilled water and culture medium was $413 \mathrm{~nm}$ and $271 \mathrm{~nm}$ and that of the quartz particles $1114 \mathrm{~nm}$ and $1843 \mathrm{~nm}$, respectively.

\section{Viability of PCLS}

PCLS with a thickness of $250 \mu \mathrm{m}$ were prepared from Wistar rats and subsequently cultured in DMEM/F-12 Ham. Viability 
was determined at $4,24,48$, and $72 \mathrm{~h}$ after incubation in medium by three different test assays: LDH-assay, live/dead staining, and WST-1 assay.

As LDH is present in the cytoplasm of cells, detection of LDH in the culture medium of PCLS indicates a loss of cell membrane integrity. Therefore, LDH release is a direct measure of a cytotoxic response or an indirect measure of cell viability. As displayed in Figure 1, the LDH release slightly increased over time, reaching $14 \%$ of total LDH after $72 \mathrm{~h}$.

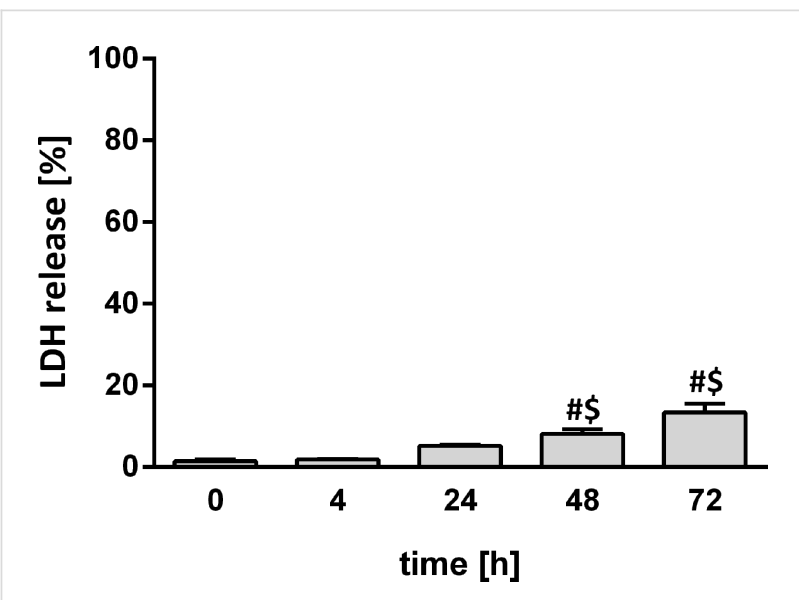

Figure 1: Cell viability as measured by $L D H$ release in PCLS culture medium at $0,4,24,48$, and $72 \mathrm{~h}$ after preparation of PCLS. Results were calculated as percentage of the positive control (Triton X-100lysed PCLS) ( $n=5 ;{ }^{\#} p<0.05$ vs $0 h ;{ }^{\$} p<0.05$ vs $4 \mathrm{~h}$ determined by ANOVA on ranks with post hoc Tukey test).

To corroborate the findings revealed by the LDH assay, we used live/dead staining as an additional viability test. While the ratio of spots (nuclei of dead cells)/volume (cytoplasm of living cells) did not change between 4 and $24 \mathrm{~h}$ of incubation, the ratio of spots/volume was doubled after 48 and $72 \mathrm{~h}$ indicating a slight decrease in viability over time (Table 1 ).

Table 1: Viability of PCLS determined by live/dead staining at 4, 24, 48 , and $72 \mathrm{~h}$ after preparation of PCLS.

\begin{tabular}{ll} 
culture time & nuclei $($ diameter $\geq 4 \mu \mathrm{m}) /$ volume $\left(10^{5} \mu \mathrm{m}^{3}\right)$ \\
\hline $4 \mathrm{~h}$ & $14 \pm 1.4$ \\
$24 \mathrm{~h}$ & $13 \pm 3.0$ \\
$48 \mathrm{~h}$ & $27 \pm 1.2^{\mathrm{a}}$ \\
$72 \mathrm{~h}$ & $29 \pm 1.9^{\mathrm{a}}$ \\
\hline
\end{tabular}

${ }^{a} p<0.05$ vs 4 and $24 \mathrm{~h}$; determined by one-way repeated measures ANOVA with post hoc Tukey test.

In a third viability test, the mitochondrial activity was measured by using WST-1 conversion. Interestingly, the mitochondrial activity increased after $24 \mathrm{~h}$ and persisted up to $72 \mathrm{~h}$ (Figure 2).

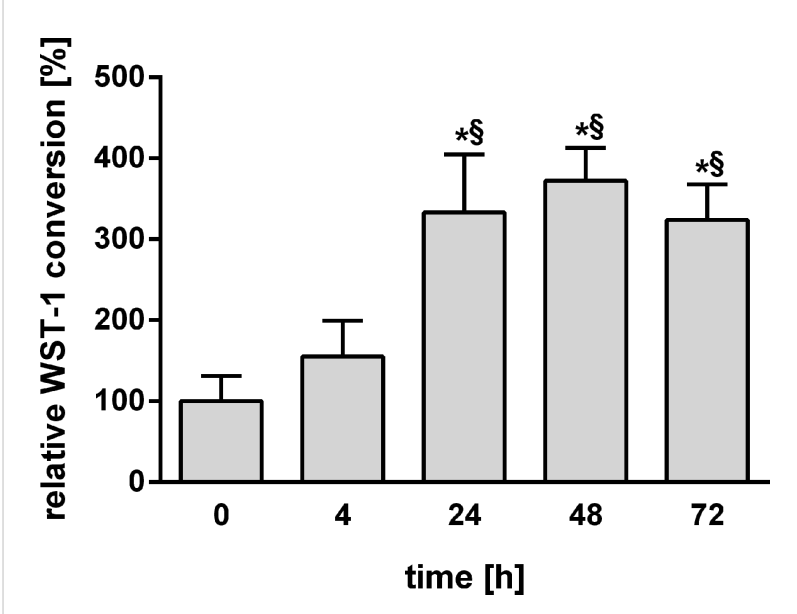

Figure 2: Viability of PCLS as determined by WST-1 conversion at 0 , $4,24,48$, and $72 \mathrm{~h}$ after preparation of PCLS $\left(n=5 ;{ }^{*} p<0.05\right.$ vs $0 \mathrm{~h}$; $\S_{p}<0.05$ vs $4 \mathrm{~h}$ determined by one-way ANOVA with post hoc Tukey test).

Since an increased WST-1 conversion could also indicate cell proliferation, we examined if there was enhanced cell proliferation by performing a proliferation assay $\left(\right.$ Click-i ${ }^{\circledR}$ EdU Alexa Fluor $^{\circledR} 488$ Imaging Kit) in which the incorporation of 5-ethynyl-2'-deoxyuridine, a nucleoside analogue to thymidine, into replicated DNA can be visualized by confocal laser scanning microscopy. As shown in Figure 3, cell proliferation was not significantly altered as shown by this assay.

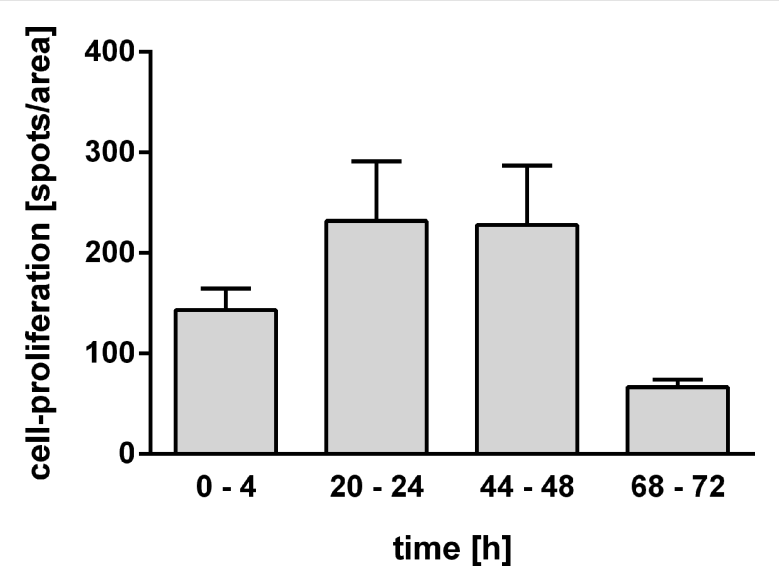

Figure 3: Cell proliferation in PCLS as determined by Click-iT ${ }^{\circledR}$ EdU Alexa Fluor ${ }^{\circledR} 488$ Imaging Kit (Invitrogen) at four different time frames ( $n=4$ PCLS per time point, three different areas; no significant differences).

\section{Responses of PCLS after exposure to (nano)particles \\ Cytotoxic response}

After $4 \mathrm{~h}$ of incubation with 20 and $30 \mu \mathrm{g} / \mathrm{mL} \mathrm{Ag-NPs,} \mathrm{the}$ LDH release was slightly increased to $4 \%$, while exposure to 
$\mathrm{ZnO}-\mathrm{NPs}$ and quartz particles did not result in increased LDH levels, indicating no cytotoxic response to these particles at this early time point. However, after incubation over $24 \mathrm{~h}$, exposure to Ag-NPs caused a dose-dependent increase in LDH release of $8 \%$ and $13 \%$ after exposure to 20 and $30 \mu \mathrm{g} / \mathrm{mL} \mathrm{Ag-NPs,} \mathrm{res-}$ pectively. Moreover, $24 \mathrm{~h}$ of incubation with $\mathrm{ZnO}-\mathrm{NPs}$ elicited a strong LDH release of $28 \%$, while quartz particles did not induce a cytotoxic response (Figure 4).

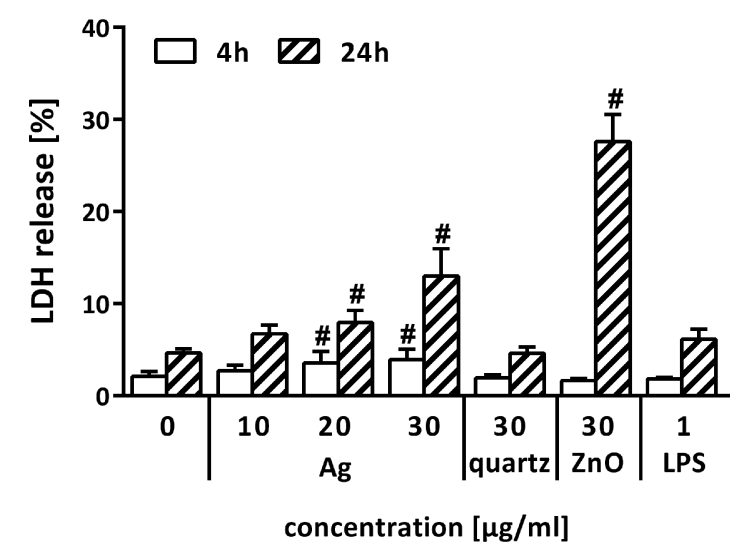

Figure 4: Cytotoxic response of PCLS as measured by LDH release after 4 and $24 \mathrm{~h}$ incubation. Results were calculated as percentage of the total LDH content, while Triton X-100 (Triton) lysed PCLS served as positive control with $100 \% \mathrm{LDH}$ release $\left(n=5 ;{ }^{*} p<0.05\right.$ vs control determined by ANOVA on ranks with post hoc

Student-Newman-Keuls test).

WST-1 conversion was measured as an additional cytotoxicity test. The mitochondrial activity did not change significantly after 4 and $24 \mathrm{~h}$ of incubation with Ag-NPs and quartz particles in comparison to controls. However, WST-1 conversion was decreased after 4 and $24 \mathrm{~h}$ of exposure to $\mathrm{ZnO}-\mathrm{NPs}$ to $47 \%$ and to positive control level (PCLS treated with $1 \%$ Triton-X), res- pectively, again indicating a strong cytotoxic effect of these particles (Figure 5).

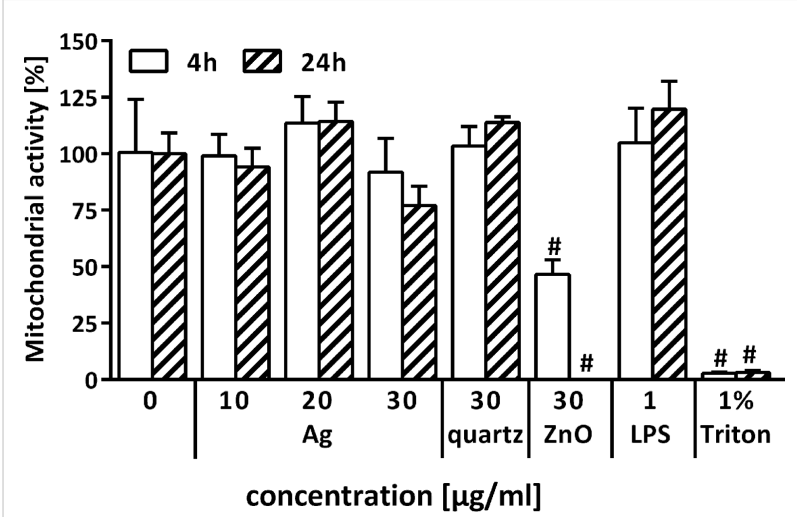

Figure 5: Cytotoxic response of PCLS as measured by WST-1 conversion after 4 and $24 \mathrm{~h}$ incubation $\left(n=5{ }^{*}{ }^{*} p<0.05\right.$ vs control determined by ANOVA on ranks with post hoc Student-Newman-Keuls test).

\section{Proinflammatory response}

The proinflammatory response in PCLS to NPs was quantified by measuring the levels of CXCL-1 and TNF- $\alpha$ in the PCLS culture medium through ELISA. The CXCL-1 release was not affected by incubation with Ag-NPs and quartz particles, while exposure to $\mathrm{ZnO}-\mathrm{NPs}$ induced a slight decrease after $4 \mathrm{~h}$ of incubation. Exposure to lipopolysaccharide (LPS, positive control) elicited an increase in CXCL-1 levels after $4 \mathrm{~h}$ (Figure 6A). The release of TNF- $\alpha$ after $4 \mathrm{~h}$ was slightly decreased upon incubation with $30 \mu \mathrm{g} / \mathrm{mL}$ Ag-NPs, quartz particles, and ZnO-NPs, while LPS induced a strong increase in TNF- $\alpha$ levels. Whereas incubation of PCLS with Ag-NPs or quartz particles for $24 \mathrm{~h}$ did not induce a change in TNF- $\alpha$ levels, exposure to $\mathrm{ZnO}$-NPs again resulted in a slight decrease in comparison to control levels (Figure 6B).
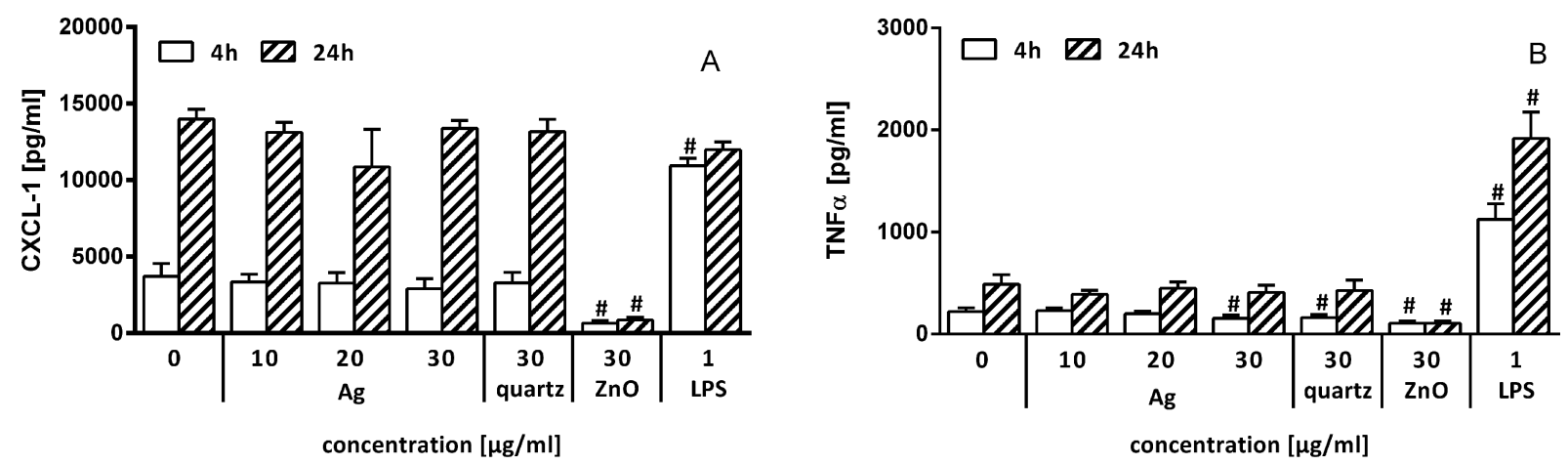

Figure 6: A: CXCL-1 levels measured in the PCLS culture medium after 4 and $24 \mathrm{~h}$ of incubation; B: TNF- $\alpha$-levels measured in the PCLS culture medium after 4 and $24 \mathrm{~h}$ of incubation; $n=5$; ${ }^{*} p<0.05$ vs control determined by ANOVA on ranks with post hoc Student-Newman-Keuls test. 


\section{Localization of Ag-NPs in PCLS by using multi- photon microscopy}

To visualize the localization of NPs in PCLS after incubation, we employed multiphoton microscopy on PCLS exposed to Ag-NPs. By examining a median cross-cryosection of PCLS incubated with $30 \mu \mathrm{g} / \mathrm{mL}$ Ag-NPs for $24 \mathrm{~h}$, a non-uniform distribution of Ag-NP aggregates/agglomerates was detected. As depicted in Figure 7, Ag-NP aggregates/agglomerates were predominantly localized on the upper cut surface of PCLS, a small amount on the lower cut surface and only a few Ag-NPs were found in inner tissue regions.

\section{Discussion}

PCLS are already an established ex vivo alternative to in vitro and in vivo examinations in pharmacotoxicology. The aim of the present study was to evaluate the potential of PCLS as a tool in nanotoxicology studies.

First of all, we assessed the viability of PCLS over time by three different viability assays. The performance of more than just one viability test is essential as every test measures a different factor and, additionally, interference of particles with the test assay has been already described [21,22]. Taken together, a slight decrease in viability over time was detected which is also in line with results of previous studies with PCLS prepared from Wistar rat, guinea pig, and human lung tissue $[10,11,23]$. Also the viability of PCLS determined through live/ dead staining slightly decreased over time, but PCLS were found to be still viable $72 \mathrm{~h}$ after preparation. Moreover, viability of PCLS was determined through WST-1 assay. The results of the WST-1 assay suggest that the viability of PCLS was improved $24 \mathrm{~h}$ after preparation. As WST-1 conversion is also an indicator for proliferation, we performed an additional proliferation assay that did not show significant differences in proliferation over time. The increase in mitochondrial activity after $24 \mathrm{~h}$ might be explained as recovery of the cells after the slicing procedure as it has been described already elsewhere $[6,11]$. Nevertheless, it has also been reported that the cutting process possibly induces the release of mitogenic factors that cause enhanced proliferation [24]. Taken together, the experimental findings of all three viability tests indicate that PCLS, in our hands, are viable for at least $72 \mathrm{~h}$.

The aim of this study was to determine the suitability of PCLS as an alternative test system in nanotoxicology. Therefore, we assessed the cytotoxic and proinflammatory response of PCLS to Ag-NPs through LDH assay, WST-1 assay, and CXCL-1 and TNF- $\alpha$ ELISAs. The PVP-coated Ag-NPs used in this study have been already demonstrated to induce a cytotoxic and/or proinflammatory response in vivo and in vitro $[25,26]$. Moreover, $\mathrm{ZnO}$-NPs served as a soluble control and quartz particles as a non-soluble control, since both particle types have been shown to elicit cytotoxic as well as inflammatory responses in both in vitro and in vivo assays [27,28].

Interestingly enough, the PVP-coated Ag-NPs used in this study only induced a slight cytotoxic, but not an inflammatory response in PCLS. However, these NPs induced cytotoxicity in human mesenchymal stem cells and peripheral blood mononuclear cells in vitro when incubated at a concentration of $25 \mu \mathrm{g} / \mathrm{mL}$ or higher [29,30]. Additionally, these NPs elicited a cytotoxic and inflammatory response in rat lungs $24 \mathrm{~h}$ after intratracheal instillation of $80 \mu \mathrm{L} \mathrm{Ag-NPs}$ at a concentration of $250 \mu \mathrm{g} / \mathrm{mL}$ [25]. Furthermore, quartz particles did not appear to cause a loss in viability or proinflammatory response, although a cytotoxic and/or inflammatory effect has been described after exposure to quartz particles in vitro as well as in vivo [28,3133]. In particular, Beyerle et al. have demonstrated that quartz particles (the same as those in the present study) induced a loss in membrane integrity in vitro in murine alveolar epithelial cells and macrophages after $24 \mathrm{~h}$ of incubation [31]. Furthermore, cytotoxicity elicited by quartz particles has been shown in vivo

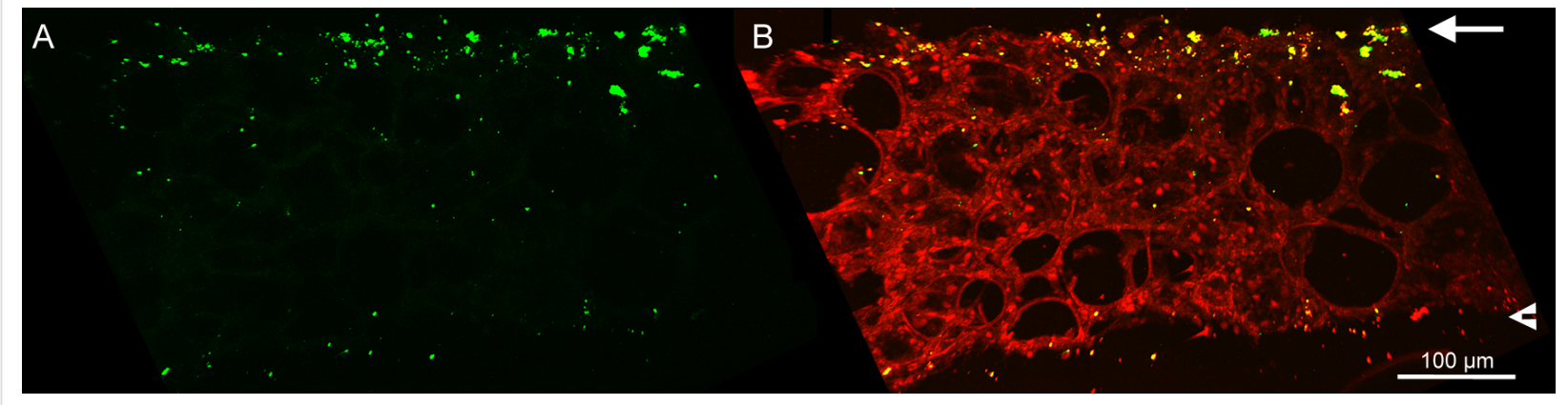

Figure 7: Multiphoton microscopy of Ag-NPs in the lung tissue. Image of an $80 \mu \mathrm{m}$ median cryosection of PCLS incubated for $24 \mathrm{~h}$ with Ag-NPs $(30 \mu \mathrm{g} / \mathrm{mL})$. Red: signal of lung tissue; green: signal of Ag-NPs aggregates/agglomerates. A: green signal; B: merge of red and green signal. The arrows mark the upper cut surface, the arrow heads the lower cut surface. 
by evaluation of bronchoalveolar lavage fluids and lung tissue of rats after intratracheal instillation [24,28]. In contrast, $\mathrm{ZnO}$ NPs induced a strong cytotoxic effect after 4 and $24 \mathrm{~h}$ of incubation, which is in line with results of a previous report [20]. In this study, cytotoxicity was determined after a $24 \mathrm{~h}$ exposure of PCLS, also prepared from Wistar rats, to ZnO-NPs (the same as those in our study) or carbon nanotubes that induced either a marked or no cytotoxic response, respectively. Furthermore, a strong cytotoxic response after exposure with $\mathrm{ZnO}-\mathrm{NPs}$ has been reported in several in vitro and in vivo studies [27,34-37]. However, the loss in viability after $\mathrm{ZnO}-\mathrm{NP}$ exposure is presumed to be mainly induced by the release of $\mathrm{Zn}^{2+}$ ions [37] The dissolution of NPs into toxic ions seems to be an important factor regarding the toxicity of the material $[38,39]$. Dissolution and therefore release of $\mathrm{Zn}^{2+}$ ions in the culture medium has been already described for the $\mathrm{ZnO}-\mathrm{NPs}$ used in the present study [40]. Moreover, the dissolution (50 to $60 \%$ within $24 \mathrm{~h}$ ) of $\mathrm{ZnO}-\mathrm{NPs}$ in cell culture medium facilitates an interaction of $\mathrm{Zn}^{2+}$ ions with cells [27]. Ag-NPs were shown to dissolve after immersion in water in the presence of oxygen under the release of $\mathrm{Ag}^{+}$ions [30,41]. However, their dissolution in biological environments is still poorly understood and will be influenced by the presence of biomolecules such as proteins $[42,43]$. Taken together, the viability of PCLS only decreased after exposure to ZnO-NPs, but not after exposure to quartz particles and only slightly after exposure to Ag-NPs.

Moreover, we determined the proinflammatory response of PCLS upon particle exposure. Surprisingly, none of the used materials induced a proinflammatory effect, although ZnO-NPs as well as quartz particles have been shown to induce inflammatory responses in the lung [27,28,34,36,37]. The low levels of CXCL-1 and TNF- $\alpha$ after exposure to ZnO-NP are probably due to the fact that most of the cells are already dead, as determined by the WST-1 assay. In summary, PCLS did not react with the release of proinflammatory cytokines upon exposure to the particles at the concentrations tested here.

The low cytotoxic response to Ag-NPs, the absent cytotoxic response to quartz particles, and also the non-existent inflammatory response to all particles are in contrast to studies using these particles in conventional in vitro and in vivo assays. Consequently, the question was whether and to what extent the particles interacted with the PCLS under submerged conditions. Therefore, we employed multiphoton microscopy to visualize the localization of Ag-NPs in and on PCLS after $24 \mathrm{~h}$ of incubation. Recently, our group has demonstrated that third harmonic generation (THG) microscopy, which is based on optical effects induced by specific inherent physical properties of a specimen, allows high-resolution label-free 3D visualization of cellular and tissue structures in intact muscle of living mice [44]. This technique allowed us to record images of Ag-NPs and lung tissue without additional labelling, since Ag-NPs exhibit strong two-photon-induced photoluminescence and enhanced THG signals through surface plasmon resonance $[45,46]$. As shown by multiphoton microscopy, the Ag-NPs were predominantly localized at the upper cut surface of PCLS as aggregates/ agglomerates and only at a much lower extent in in deeper regions of the tissue slice. This indicates that the majority of the particles did not have the chance to interact with all cells present in the tissue slice since the Ag-NPs with their hydrodynamic diameter of $116 \mathrm{~nm}$ are too large for diffusional transport through the tissue. In contrast, the $\mathrm{Zn}^{2+}$ ions released by the $\mathrm{ZnO}$-NPs are able to travel by diffusion, resulting in the strong cytotoxic response of PCLS we have measured in this study. These findings suggest that the interaction of non-soluble NPs with the majority of cells present in a given PCLS appears to be limited.

\section{Conclusion}

Although a recently published study demonstrated that PCLS are able to detect different early effects of NP toxicity, it is still not clear whether PCLS possess an added value in detecting nanomaterial pulmonary toxicity [47]. Here we show that there was no cytotoxic response of PCLS to micron-sized quartz particles, only a slight cytotoxic response to PVP-coated Ag-NPs, but a strong cytotoxic response to uncoated ZnO-NPs. Moreover, none of the materials induced a proinflammatory effect in PCLS. Furthermore, we were able to show by multiphoton microscopy that the majority of Ag-NPs was localized on the cut surface of the PCLS and not able to translocate into inner regions of the tissue slice. Based on these findings, we conclude that PCLS may have some limitations when used in nanotoxicology studies. However, a definite conclusion can be only drawn after testing also other types and concentrations of NPs as well as using other more sensitive analysis methods to assess possible cell responses.

\section{Experimental}

\section{Particles}

PVP-coated Ag-NPs were prepared as described before $[30,48]$. Briefly, Ag-NPs were synthesized by reduction with glucose in the presence of PVP and dispersed in ultrapure degassed water. The silver concentration was determined by atomic absorption spectroscopy (AAS) with a detection limit of $1 \mu \mathrm{g} \cdot \mathrm{L}^{-1}$. SEM was performed with a FEI Quanta 400 ESEM instrument in high vacuum without sputtering. Particle size distribution and PDI were measured by DLS with a Malvern Zetasizer Nano ZS (Malvern Instruments GmbH, Herrenberg, Germany).

The uncoated ZnO-NPs NM110 belonged to a set of representative manufactured nanomaterials provided and characterized 
by the European Commission Joint Research Centre (JRC, Ispra, Italy). Particle size distribution was determined by DLS. Shortly before incubation with PCLS, ZnO-NPs were dispersed following the Nanogenotox dispersion protocol [49].

The quartz particles (Min-U-Sil 5, crystalline silica, $\alpha$-quartz) with a purity of $98 \% \mathrm{SiO}_{2}$ were obtained from US Silica Company (Berkeley Springs, WV, USA). Immediately before incubation with PCLS, quartz particles were dispersed at a concentration of $1 \mathrm{mg} / \mathrm{mL}$ in distilled water. Subsequently, the suspension was vortexed for $1 \mathrm{~min}$ followed by ultrasonic bath for $1 \mathrm{~min}$. This procedure was repeated three times.

\section{Animals}

Female Wistar rats (Wistar RjHan:WI rats), 8-10 weeks of age (approx. $250 \mathrm{~g}$ body weight), were obtained from Janvier (Le Genest Saint Isle, France). The animals had at least one week for acclimatization and were housed in pairs in standard Makrolon plastic cages type IV on a 12 hour day/night circle. Rodent diet and water were provided ad libitum.

\section{Preparation of PCLS}

Under isoflurane anaesthesia, rats were sacrificed by exsanguination through the abdominal aorta. Lungs were filled with $15 \mathrm{~mL}$ of a $1.5 \%$ low gelling temperature agarose solution in situ. After five minutes the lungs were extracted and cooled in an ice-cooled Earl's Balanced Salt Solution for $10 \mathrm{~min}$. Punched out cylinders (diameter $8 \mathrm{~mm}$ ) of these lungs were cut into approximately 250 micrometre thin slices by using a Krumdieck tissue slicer (microtome; Alabama Research and Development, Munford, AL, USA). Always four PCLS per well (24-well plate) were cultured in Dulbecco's modified Eagle's medium/nutrient mixture F-12 Ham (DMEM/F-12 Ham) containing 100 units $/ \mathrm{mL}$ penicillin and $100 \mu \mathrm{g} / \mathrm{mL}$ streptomycin. The 24-well plates were placed on a plate shaker in the incubator $\left(5 \% \mathrm{CO}_{2}, 100 \%\right.$ humidity, $\left.37{ }^{\circ} \mathrm{C}\right)$. Prior to incubation, the PCLS were placed in a 24-well culture dish in the incubator for re-melting the agarose and washed for $1 \mathrm{~h}$ by changing the culture medium three times, in order to remove the agarose.

\section{Incubation of PCLS}

For viability testing, PCLS were incubated with $500 \mu \mathrm{L}$ DMEM/F-12 Ham for 4, 24, 48, and 72 h. For particle exposure experiments PCLS were exposed for 4 and $24 \mathrm{~h}$ to $500 \mu \mathrm{L}$ DMEM/F-12 Ham either with PVP-Ag-NPs (10, 20, and $30 \mu \mathrm{g} / \mathrm{mL}$ ), $30 \mu \mathrm{g} / \mathrm{mL} \mathrm{ZnO}-N P s$, or $30 \mu \mathrm{g} / \mathrm{mL}$ quartz particles. Therefore, after the $1 \mathrm{~h}$ washing procedure, culture medium used for washing was replaced by the particular suspension. Additionally, PCLS were incubated only with $500 \mu \mathrm{L}$ DMEM/ F-12 or with $500 \mu \mathrm{L}$ DMEM/F-12 with $1 \mu \mathrm{g} / \mathrm{mL}$ LPS, which served as negative and positive (inflammatory) control. Further- more, PCLS were lysed by adding $1 \%$ Triton X-100 which was used as positive (cytotoxic) control. All incubations were performed in duplicates.

\section{Determination of LDH release in PCLS culture medium}

LDH release was determined in PCLS culture medium using the Cytotoxicity Detection Kit ${ }^{\text {PLUS }}$ (LDH) (Roche, Mannheim, Germany). Triton X-100 lysed PCLS were used as positive controls (100\% LDH release). Results were calculated as percentage of the total LDH content. All tests were performed in duplicates.

\section{Live/dead staining}

Viability of PCLS was determined after 4, 24, 48, and $72 \mathrm{~h}$ by using the LIVE/DEAD ${ }^{\circledR}$ Viability/Cytotoxicity Kit for mammalian cells (Invitrogen, Karlsruhe, Germany). PCLS were incubated with $4 \mu \mathrm{M}$ calcein acetoxymethyl (calcein AM) and $4 \mu \mathrm{M}$ ethidium-homodimer-1 (EthD-1) for $45 \mathrm{~min}$ at room temperature. Live cells enzymatically convert calcein AM in fluorescent calcein, while EthD-1 enters dead cells through the damaged membrane, binds to their nuclei, and emits red fluorescence. Immediately after the staining procedure, PCLS were mounted in phosphate buffered saline (PBS) on glass slides and observed by using a Leica SP5 confocal laser-scanning microscope (cLSM, Leica Microsystems, Wetzlar, Germany) with a PlanFluotar objective (Leica; 20×; NA 0.5). The excitation wavelength was $488 \mathrm{~nm}$ and the emission was detected at $510-540 \mathrm{~nm}$ for calcein and 580-620 nm for EthD-1. Optical $z$-sections covering $30 \mu \mathrm{m}$ depth of the PCLS ( $z$-distance $1 \mu \mathrm{m})$ were recorded by using the same settings for all samples. Images were processed and analysed with Imaris software (Bitplane, Zürich Switzerland). For quantification of dead cells, the Imaris spotfinder algorithm was applied to automatically identify and count labelled cell nuclei in these 3D volumes and the volume of live cells was identified and calculated by using the surface tool. Similarly, as already described in Henjacovic et al. [8], viability was determined as ratio of nuclei of dead cells per volume of live cells (spots (diameter $\leq 4 \mu \mathrm{m}$ )/volume $\left(10^{5} \mu \mathrm{m}^{3}\right)$.

\section{WST-1 reduction in PCLS culture medium}

The WST-1 assay (Roche Diagnostics, Mannheim, Germany) was used for spectrometric quantification of cellular viability. After removing cell culture medium, PCLS were incubated for $1 \mathrm{~h}$ with $500 \mu \mathrm{L}$ freshly prepared WST-1 solution (manufacturer protocol) diluted 1:10 in DMEM/F-12 Ham. Absorbance was determined at a wavelength of $450 \mathrm{~nm}$. Results are given in percentage of control. The relative WST-1 conversion was calculated as percentage of control (WST-1 conversion at $0 \mathrm{~h}$ ). All tests were performed in duplicates. 


\section{Cell proliferation assay}

For determination of cell proliferation, the Click-iT ${ }^{\circledR}$ EdU Alexa Fluor ${ }^{\circledR} 488$ Imaging Kit (Invitrogen, Karlsruhe, Germany) was used. PCLS were incubated for $4 \mathrm{~h}$ with $20 \mu \mathrm{M}$ EdU (5-ethynyl-2'-deoxyuridine, a nucleoside analogue to thymidine) at $0,20,44$, and $68 \mathrm{~h}$ after preparation. Subsequently, four PCLS per time point were fixed with buffered 4\% paraformaldehyde (Microcos $\mathrm{GmbH}$, Saaldorf-Surheim, Germany) at room temperature for $15 \mathrm{~min}$. Then PCLS were washed twice in PBS supplemented with $3 \%$ bovine albumin serum (BSA) and stored at $4{ }^{\circ} \mathrm{C}$ until further processing. The EdU staining was conducted as described by the manufacturer. Briefly, after permeabilization (with PBS, supplemented with $3 \%$ BSA and $0.5 \%$ Triton X-100 (Sigma-Aldrich, Munich, Germany), PCLS were incubated with the EdU Click-iT ${ }^{\circledR}$ reaction cocktail followed by another washing step and finally mounted in PermaFluor (Thermo Scientific, Fremont, CA, USA) on a glass slide. Images were acquired with the cLSM (see details above). Excitation wavelength was $488 \mathrm{~nm}$ and emission was detected at 510-600 nm. Optical $z$-sections covering the complete depth of the PCLS ( $z$-size $250 \mu \mathrm{m}, z$-distance $3 \mu \mathrm{m}$ ) were recorded by using the same settings for all samples. Images were processed and analyzed by using Imaris software (Bitplane, Zürich, Switzerland). For quantification of EdU positive cells, the Imaris spotfinder algorithm was applied to automatically identify and count labelled cell nuclei in three 3D-volumes ( $x y$-size $500 \mu \mathrm{m}, z$-size $250 \mu \mathrm{m}$ ) from each PCLS sample.

\section{Quantification of TNF- $\alpha$ and CXCL-1 in the PCLS-culture medium by ELISA}

The proinflammatory cytokines TNF- $\alpha$ and CXCL-1 were measured in PCLS supernatants by using commercially available enzyme-linked immunosorbent assay kits (ELISA, DuoSet, $\mathrm{R} \& \mathrm{D}$, Wiesbaden-Nordenstadt, Germany) according to the specifications of the manufacturer. Absorbance was determined at a wave length of $450 \mathrm{~nm}$ (Tecan Infinite F200).

\section{Multiphoton microscopy}

PCLS incubated with $30 \mu \mathrm{g} / \mathrm{mL}$ of Ag-NPs for $24 \mathrm{~h}$ were fixed in $70 \%$ ethanol until further processing. Before cryosectioning, PCLS were embedded in Tissue-Tek OCT compound (Miles, Inc. Diagnostic Division, Elkhart, IN) and frozen until hardening. Then 60 to $80 \mu \mathrm{m}$ thick cross sections of PCLS were cut with a cryostat microtome (Microm HM560, Thermo scientific, Waltham, MA, USA), transferred on a glass slide, and coverslipped immediately.

Two-photon microscopy on PCLS sections incubated with Ag-NPs $(30 \mu \mathrm{g} / \mathrm{mL})$ was performed on a TriMScope (LaVision Biotec, Bielefeld, Germany) built around an Olympus BX 51 microscope (Olympus, Hamburg, Germany) and equipped with a tunable Ultra II Ti:sapphire laser (Coherent, Dieburg, Germany) and an optical parametric oscillator (Chameleon OPO; APE, Berlin, Germany), which is pumped by the Ti:sapphire laser. The OPO generated $1275 \mathrm{~nm}$ light with 640-700 mW output. The attenuated intensity at the sample was $170 \mathrm{~mW}$. An Olympus XLUMPlanF1 20×/0.95W objective was used to acquire optical sections $(z$-size: $85 \mu \mathrm{m}, z$-distance: 1 $\mu \mathrm{m}, x y: 500 \times 500 \mu \mathrm{m}$ with $1035 \times 1035$ pixels and 400 lines per second).

The Ag-NP signal was (epi-)detected at 604-644 nm, THG signal was detected in the forward direction at $(417-477 \mathrm{~nm})$. $700 \mathrm{~nm}$ short pass filters blocked out excitation light. Light collection in forward direction was performed by an Olympus WI-UCD condenser, NA 0.8. Photomultiplier tubes were gallium arsenide phosphide detectors (Hamamatsu H7422-40). Images were processed and 3D rendered by using Imaris software (Bitplane, Zürich, Switzerland).

\section{Statistical analysis}

Data in the figures are given as mean \pm SEM (standard error of the mean). Statistical analysis was performed for normalized data by one-way ANOVA with post hoc Tukey test. Other data were analyzed by repeated measures ANOVA on ranks followed by a post hoc test as stated individually (Software: SigmaStat for Windows, Jandel Scientific, Erkrath, Germany). Differences were considered statistically significant at $p<0.05$.

\section{Acknowledgements}

We would like to thank Alexander Dietrich and Thomas Gudermann from the Walther-Straub Institute for Pharmacology and Toxicology, LMU Munich, for providing the Krumdieck tissue slicer. Moreover, we would like to thank Claudia Fahney for her excellent technical assistance. Many thanks also to Tobias Stöger from the Helmholtz Center in Munich for providing the quartz particles (Min-U-Sil 5, crystalline silica, $\alpha$-quartz). This work was financed by the German Research Foundation (DFG) within the Priority Programme "Biological Responses to Nanoscale Particles” (SPP1313).

\section{References}

1. Maynard, A. D.; Warheit, D. B.; Philbert, M. A. Toxicol. Sci. 2011, 120 (Suppl. 1), S109-129. doi:10.1093/toxsci/kfq372

2. Bach, P. H.; Vickers, A. E. M.; Fisher, R.; Baumann, A.; Brittebo, E.; Carlile, D. J.; Koster, H. J.; Lake, B. G.; Salmon, F.; Sawyer, T. W.; Skibinski, G. ATLA, Altern. Lab. Anim. 1996, 24, 893-923.

3. Russell, W. M. S.; Burch, R. L. The principles of humane experimental technique; Muethen and Co. Ltd.: London, United Kingdom, 1959.

4. Parrish, A. R.; Gandolfi, A. J.; Brendel, K. Life Sci. 1995, 57, 1887-1901. doi:10.1016/0024-3205(95)02176-J 
5. Morin, J.-P.; Baste, J.-M.; Gay, A.; Crochemore, C.; Corbiére, C.; Monteil, C. Xenobiotica 2013, 43, 63-72. doi:10.3109/00498254.2012.727043

6. Liberati, T. A.; Randle, M. R.; Toth, L. A. Expert Rev. Mol. Diagn. 2010, 10, 501-508. doi:10.1586/erm.10.21

7. Davidovich, N.; Huang, J.; Margulies, S. S. Am. J. Physiol.: Lung Cell. Mol. Physiol. 2013, 304, L210-L220. doi:10.1152/ajplung.00224.2012

8. Henjakovic, M.; Sewald, K.; Switalla, S.; Kaiser, D.; Müller, M.; Veres, T. Z.; Martin, C.; Uhlig, S.; Krug, N.; Braun, A. Toxicol. Appl. Pharmacol. 2008, 231, 68-76. doi:10.1016/j.taap.2008.04.003

9. Veres, T. Z.; Voedisch, S.; Spies, E.; Tschernig, T.; Braun, A. Am. J. Pathol. 2011, 179, 603-609. doi:10.1016/j.ajpath.2011.04.039

10. Ressmeyer, A. R.; Larsson, A. K.; Vollmer, E.; Dahlén, S. E.; Uhlig, S.; Martin, C. Eur. Respir. J. 2006, 28, 603-611. doi:10.1183/09031936.06.00004206

11. Martin, C.; Uhlig, S.; Ullrich, V. Eur. Respir. J. 1996, 9, 2479-2487. doi:10.1183/09031936.96.09122479

12. Martin, C.; Uhlig, S.; Ullrich, V. Am. J. Respir. Cell Mol. Biol. 2001, 24, 139-145. doi:10.1165/ajrcmb.24.2.3545

13. Schleputz, M.; Rieg, A. D.; Seehase, S.; Spillner, J.; Perez-Bouza, A.; Braunschweig, T.; Schroeder, T.; Bernau, M.; Lambermont, V.; Schlumbohm, C.; Sewald, K.; Autschbach, R.; Braun, A.; Kramer, B. W.; Uhlig, S.; Martin, C. PLoS One 2012, 7, e47344. doi:10.1371/journal.pone.0047344

14. Henjakovic, M.; Martin, C.; Hoymann, H. G.; Sewald, K.; Ressmeyer, A. R.; Dassow, C.; Pohlmann, G.; Krug, N.; Uhlig, S.; Braun, A. Toxicol. Sci. 2008, 106, 444-453. doi:10.1093/toxsci/kfn178

15. Nassimi, M.; Schleh, C.; Lauenstein, H. D.; Hussein, R.; Hoymann, H. G.; Koch, W.; Pohlmann, G.; Krug, N.; Sewald, K.; Rittinghausen, S.; Braun, A.; Müller-Goymann, C.

Eur. J. Pharm. Biopharm. 2010, 75, 107-116. doi:10.1016/j.ejpb.2010.02.014

16. Nassimi, M.; Schleh, C.; Lauenstein, H.-D.; Hussein, R.; Lübbers, K.; Pohlmann, G.; Switalla, S.; Sewald, K.; Müller, M.; Krug, N.; Müller-Goymann, C. C.; Braun, A. Inhalation Toxicol. 2009, 21 (Suppl. 1), 104-109. doi:10.1080/08958370903005769

17. Neuhaus, V.; Schwarz, K.; Klee, A.; Seehase, S.; Forster, C.; Pfennig, O.; Jonigk, D.; Fieguth, H. G.; Koch, W.; Warnecke, G.; Yusibov, V.; Sewald, K.; Braun, A. PLoS One 2013, 8, e71728. doi:10.1371/journal.pone.0071728

18. Paranjpe, M.; Neuhaus, V.; Finke, J. H.; Richter, C.; Gothsch, T.; Kwade, A.; Büttgenbach, S.; Braun, A.; Müller-Goymann, C. C. Inhalation Toxicol. 2013, 25, 536-543. doi:10.3109/08958378.2013.810315

19. Wohlleben, W.; Kolle, S. N.; Hasenkamp, L.-C.; Böser, A.; Vogel, S.; von Vacano, B.; van Ravenzwaay, B.; Landsiedel, R. J. Phys.: Conf. Ser. 2011, 304, 012061. doi:10.1088/1742-6596/304/1/012061

20. Wohlleben, W.; Meier, M. W.; Vogel, S.; Landsiedel, R.; Cox, G.; Hirth, S.; Tomović, Z. Nanoscale 2013, 5, 369-380. doi:10.1039/c2nr32711b

21. Monteiro-Riviere, N. A.; Inman, A. O.; Zhang, L. W. Toxicol. Appl. Pharmacol. 2009, 234, 222-235. doi:10.1016/j.taap.2008.09.030

22. Wörle-Knirsch, J. M.; Pulskamp, K.; Krug, H. F. Nano Lett. 2006, 6, 1261-1268. doi:10.1021/nl060177c
23. Wohlsen, A.; Martin, C.; Vollmer, E.; Branscheid, D.; Magnussen, H.; Becker, W.-M.; Lepp, U.; Uhlig, S. Eur. Respir. J. 2003, 21, 1024-1032. doi:10.1183/09031936.03.00027502

24. Vallan, C.; Friis, R. R.; Burri, P. H. Exp. Lung Res. 1995, 21, 469-487. doi:10.3109/01902149509023720

25. Haberl, N.; Hirn, S.; Wenk, A.; Diendorf, J.; Epple, M.; Johnston, B. D.; Krombach, F.; Kreyling, W. G.; Schleh, C. Beilstein J. Nanotechnol. 2013, 4, 933-940. doi:10.3762/bjnano.4.105

26. Chernousova, S.; Epple, M. Angew. Chem., Int. Ed. 2013, 52, 1636-1653. doi:10.1002/anie.201205923

27. Kermanizadeh, A.; Pojana, G.; Gaiser, B. K.; Birkedal, R.; Bilanicova, D.; Wallin, H.; Jensen, K. A.; Sellergren, B.; Hutchison, G. R.; Marcomini, A.; Stone, V. Nanotoxicology 2013, 7, 301-313. doi:10.3109/17435390.2011.653416

28. Warheit, D. B.; Webb, T. R.; Colvin, V. L.; Reed, K. L.; Sayes, C. M. Toxicol. Sci. 2007, 95, 270-280. doi:10.1093/toxsci/kfl128

29. Greulich, C.; Diendorf, J.; Simon, T.; Eggeler, G.; Epple, M.; Köller, M. Acta Biomater. 2011, 7, 347-354. doi:10.1016/j.actbio.2010.08.003

30. Kittler, S.; Greulich, C.; Diendorf, J.; Köller, M.; Epple, M. Chem. Mater. 2010, 22, 4548-4554. doi:10.1021/cm100023p

31. Beyerle, A.; Schulz, H.; Kissel, T.; Stoeger, T. J. Phys.: Conf. Ser. 2009, 151, 012034. doi:10.1088/1742-6596/151/1/012034

32. Cho, W.-S.; Duffin, R.; Howie, S. E. M.; Scotton, C. J.; Wallace, W. A. H.; Macnee, W.; Bradley, M.; Megson, I. L.; Donaldson, K. Part. Fibre Toxicol. 2011, 8, No. 27. doi:10.1186/1743-8977-8-27

33. Journeay, W. S.; Suri, S. S.; Moralez, J. G.; Fenniri, H.; Singh, B. Small 2008, 4, 817-823. doi:10.1002/smll.200700700

34. Sayes, C. M.; Reed, K. L.; Warheit, D. B. Toxicol. Sci. 2007, 97, 163-180. doi:10.1093/toxsci/kfm018

35. Kermanizadeh, A.; Vranic, S.; Boland, S.; Moreau, K.; Baeza-Squiban, A.; Gaiser, B. K.; Andrzejczuk, L. A.; Stone, V. BMC Nephrol. 2013, 14, 96. doi:10.1186/1471-2369-14-96

36. Wilhelmi, V.; Fischer, U.; van Berlo, D.; Schulze-Osthoff, K.; Schins, R. P.; Albrecht, C. Toxicol. In Vitro 2012, 26, 323-334. doi:10.1016/j.tiv.2011.12.006

37. Xia, T.; Kovochich, M.; Liong, M.; Mädler, L.; Gilbert, B.; Shi, H.; Yeh, J. I.; Zink, J. I.; Nel, A. E. ACS Nano 2008, 2, 2121-2134. doi:10.1021/nn800511k

38. Inoue, K.; Branigan, D.; Xiong, Z.-G. J. Biol. Chem. 2010, 285 , 7430-7439. doi:10.1074/jbc.M109.040485

39. Misra, S. K.; Dybowska, A.; Berhanu, D.; Luoma, S. N.; Valsami-Jones, E. Sci. Total Environ. 2012, 438, 225-232. doi:10.1016/j.scitotenv.2012.08.066

40. Singh, C.; Friedrichs, S.; Levin, M.; Birkedal, R.; Jensen, K. A.; Pojana, G.; Wohlleben, W.; Schulte, S.; Wiench, K.; Turney, T.; Koulaeva, O.; Marshall, D.; Hund-Rinke, K.; Kördel, W.; Van Doren, E.; De Temmerman, P.-J.; Abi Daoud Francisco, M.; Mast, J.; Gibson, N.; Koeber, R.; Linsinger, T.; Klein, C. NM-Series of Representative Manufactured Nanomaterials, Zinc Oxide NM-110, NM-111, NM-112, NM-113, Characterisation and Test Item Preparation; EUR - Scientific and Technical Research Reports; Publications Office of the European Union: 2011, 2011. doi:10.2787/55008

41. Liu, J.; Hurt, R. H. Environ. Sci. Technol. 2010, 44, 2169-2175. doi:10.1021/es9035557

42. Liu, J.; Wang, Z.; Liu, F. D.; Kane, A. B.; Hurt, R. H. ACS Nano 2012, 6, 9887-9899. doi:10.1021/nn303449n

43. Loza, K.; Diendorf, J.; Sengstock, C.; Ruiz-Gonzalez, L.; Gonzalez-Calbet, J. M.; Vallet-Regi, M.; Köller, M.; Epple, M. J. Mater. Chem. B 2014, 2, 1634-1643. doi:10.1039/c3tb21569e 
44. Rehberg, M.; Krombach, F.; Pohl, U.; Dietzel, S. PLoS One 2011, 6 , e28237. doi:10.1371/journal.pone.0028237

45. Liu, T.-M.; Tai, S.-P.; Yu, C.-H.; Wen, Y.-C.; Chu, S.-W.; Chen, L.-J.; Prasad, M. R.; Lin, K.-J.; Sun, C.-K. Appl. Phys. Lett. 2006, 89 , 043122. doi:10.1063/1.2240738

46. Tai, S.-P.; Wu, Y.; Shieh, D.-B.; Chen, L.-J.; Lin, K.-J.; Yu, C.-H.; Chu, S.-W.; Chang, C.-H.; Shi, X.-Y.; Wen, Y.-C.; Lin, K.-H.; Liu, T.-M.; Sun, C.-K. Adv. Mater. 2007, 19, 4520-4523. doi:10.1002/adma.200602213

47. Sauer, U. G.; Vogel, S.; Aumann, A.; Hess, A.; Kolle, S. N.; Ma-Hock, L.; Wohlleben, W.; Dammann, M.; Strauss, V.; Treumann, S.; Groters, S.; Wiench, K.; van Ravenzwaay, B.; Landsiedel, R. Toxicol. Appl. Pharmacol. 2014, 276, 1-20. doi:10.1016/j.taap.2013.12.017

48. Wang, H. S.; Qiao, X. L.; Chen, J. G.; Ding, S. Y. Colloids Surf., $A$ 2005, 256, 111-115. doi:10.1016/j.colsurfa.2004.12.058

49. Standard operating procedures for characterisation of the selected manufactured nanomaterials types. 2011; http://www.nanogenotox.eu/files/PDF/Deliverables/nanogenotox\%20de liverable\%202_wp4_\%20sops\%20report.pdf (accessed Oct 9, 2014).

\section{License and Terms}

This is an Open Access article under the terms of the Creative Commons Attribution License (http://creativecommons.org/licenses/by/2.0), which permits unrestricted use, distribution, and reproduction in any medium, provided the original work is properly cited.

The license is subject to the Beilstein Journal of Nanotechnology terms and conditions: (http://www.beilstein-journals.org/bjnano)

The definitive version of this article is the electronic one which can be found at: doi:10.3762/bjnano.5.253 